\title{
Effect of an Enrichment Program on DAT Scores of Potential Dental Students from Disadvantaged Backgrounds
}

\author{
Kimberly P. Johnson, Ed.M.; Marilyn Woolfolk, D.D.S., M.P.H.; \\ Kenneth B. May, D.D.S., M.S.; Marita R. Inglehart, Dr. phil. habil.
}

Abstract: The objectives of this study were to explore whether Dental Admission Test (DAT) training in an enrichment program for potential dental students increases the participants' Perceptual Achievement Test (PAT) and academic average (AA) scores and whether the length of the program and personal factors such as the number of disadvantages correlate with the DAT scores. Data were collected from 361 students in the summer enrichment program at one dental school between 1994 and 2011 . Their baseline, midpoint, and end of program PAT and AA DAT scores were collected. Seventy students self-reported official scores. These students' PAT scores increased from 14.40 at baseline to 17.09 at midpoint to 17.84 at program end ( $<<0.001)$, and their AA scores increased from 13.53 to 14.09 to 15.12 ( $\mathrm{p}<0.001)$. Their official scores were higher than the beginning scores (PAT: 14.42 vs. $16.15 ; \mathrm{p}<0.001$; AA: 13.61 vs. $16.23 ; \mathrm{p}<0.001)$. The longer the program, the more the students improved their official scores (PAT: $r=0.35 ; \mathrm{p}=0.003$; AA: $\mathrm{r}=0.24 ; \mathrm{p}=0.044$ ). The more disadvantages the students self-reported, the better their official test scores were (PAT: $r=0.40 ; p<0.001$; AA: $r=0.43$; $p<0.001$ ). This study found that the DAT training during summer enrichment programs for students from disadvantaged backgrounds led to significant improvements in their DAT scores. The longer the programs, the more the students improved; and the more disadvantages the students had, the more they benefitted.

\begin{abstract}
Ms. Johnson is Health Careers Opportunity Program Coordinator, School of Dentistry, University of Michigan; Dr. Woolfolk is Assistant Dean for Student Services and Professor of Dentistry, Department of Periodontics and Oral Medicine, School of Dentistry, University of Michigan; Dr. May is Associate Professor, Division of Prosthodontics and Director, Office of Multicultural Affairs and Recruitment Initiatives, School of Dentistry, University of Michigan; and Dr. Inglehart is Professor, School of Dentistry, University of Michigan. Direct correspondence and requests for reprints to Dr. Marita R. Inglehart, School of Dentistry, University of Michigan, 1011 North University Ave., Ann Arbor, MI 48109-1078; 734-763-8073 phone; 734-763-5503 fax; mri@umich.edu.
\end{abstract}

Keywords: dental admission test, dental school admissions, dental schools, diversity, underrepresented minority dental students, underrepresented minorities, admissions

Submitted for publication 6/8/12; accepted 9/7/12

I n 2004, the Sullivan Commission published its groundbreaking report, Missing Persons: Minorities in the Health Professions, which showed a significant discrepancy between the percentage of individuals from underrepresented minority (URM) backgrounds and the percentage of health care providers from these groups. ${ }^{1}$ While individuals from African American, Latino/a, and American Indian groups make up over 25 percent of the U.S. population, they represent only 9 percent of nurses, 6 percent of physicians, and 5 percent of dentists. In addition, the percentages of students from these URM groups are clearly underrepresented among enrolled students in health professions schools. ${ }^{2}$ One serious consequence of the underrepresentation of URM health care providers was described in the Institute of Medicine report Unequal Treatment. This report documented a direct link between poorer health outcomes for URM patients and the shortage of health care providers from these groups. ${ }^{3}$ This finding is largely due to the fact that health professionals from URM backgrounds are more likely to serve patients from these backgrounds. ${ }^{1,4-8}$ These findings raised the question of what would be viable strategies to increase the percentages of students from URM groups in health professions programs. The Sullivan Commission partially addressed this question by suggesting that universities, colleges, and health professions schools support potential students from URM and/ or socioeconomically disadvantaged backgrounds who express an interest in health care careers with services and programs such as mentoring, preparation for taking entrance exams, and enhancing their understanding of the application process. ${ }^{1}$

Research in support of these recommendations has analyzed the outcomes of enrichment programs for premedical students. The studies showed that these programs were successful in ensuring that significant numbers of their participants actually enrolled in medical school. ${ }^{8-11}$ Dental schools have 
also developed special enrichment and recruitment programs to increase the enrollment of students from URM and/or disadvantaged backgrounds. ${ }^{12}$ One such enrichment program is the Profile for Success (PFS) Program that has been offered at the University of Michigan School of Dentistry since 1994. The PFS Program is a summer enrichment program for junior and senior undergraduate students and recent college graduates from disadvantaged backgrounds. The funding for this program has been provided through grants from the U.S. Health Careers Opportunity Program (HCOP). ${ }^{13}$

The main objective of the PFS Program is to increase the participants' chances to compete successfully in the dental school admissions process. The participants therefore take a Dental Admission Test (DAT) preparation program in addition to learning about dentistry as a profession and especially about the skills needed in the dental school admission process. No studies so far have analyzed whether DAT test preparation programs actually do increase participants' scores significantly. A review of the research on the impact of commercial test preparation courses on students' performance on the Medical College Admission Test (MCAT) by McGaghie et al. in 2004 also showed a lack of solid research on this topic. ${ }^{14}$

The first objective of our study was therefore to analyze whether the participants in the PFS Program increased their Perceptual Achievement Test (PAT) and academic average (AA) scores on the DAT from the beginning to the midpoint to the end of the program, as well as whether their official DAT scores were actually significantly higher than their baseline scores at the beginning of the program. In addition, this study explored whether situational factors such as the length of the program as well as personal factors such as the number of disadvantages reported were related to the progress the students made. The PFS
Program started out as a four-week program. After six years, it was changed to a five-week program, then to six weeks and ultimately seven weeks (see Table 1 for details). We hypothesized that the longer students participated in these programs, the more their scores would improve.

Concerning the effects of personal background characteristics, the age of the students and their year in college might affect their learning experiences. These students' ages ranged from twenty to thirtyseven years, and their class standing ranged from having just finished their sophomore year of college to having been out of college for several years. Understanding whether the students' age and standing in college might affect how much they benefit from these programs could be relevant for future planning purposes. Finally, the fact that the PFS Program enrolls students from disadvantaged backgrounds raises the question whether the sum of disadvantages might be a predictor of potential improvement. Three types of disadvantages were considered in the admissions process for this program: whether the student 1) was economically disadvantaged, i.e., came from a low-income family with an annual income below the thresholds published in the Federal Register, ${ }^{15}$ 2) educationally disadvantaged, i.e., came from a community college, a less competitive four-year institution as defined by Barron's Profiles of American Colleges, ${ }^{16}$ or a high school with standardized test scores (ACT/SAT) below national norms; or 3) socially disadvantaged, i.e., came from an environment that has inhibited (but not prevented) the student from obtaining the knowledge, skills, and abilities required to enroll in and successfully complete an undergraduate course of study that could lead to a career in the health sciences. ${ }^{17}$ One could argue that a cumulative model applies for the degree to which each of these three disadvantages affects students' performance: the more disadvantages the students encounter, the

Table 1. Overview of the annual Profile for Success Program by length of program

\begin{tabular}{lcc} 
Length of Program & $\begin{array}{c}\text { Years at Each Length } \\
\text { (\% of total) }\end{array}$ & $\begin{array}{c}\text { Number of Participants at Each Length } \\
\text { (\% of total) }\end{array}$ \\
\hline 4 weeks & $6(33 \%)$ & $82(23 \%)$ \\
5 weeks & $2(11 \%)$ & $32(9 \%)$ \\
6 weeks & $8(44 \%)$ & $196(54 \%)$ \\
7 weeks & $2(11 \%)$ & $51(14 \%)$ \\
& Total Years: 18 & Total Participants: 361 \\
& & Annual Mean=20.05, SD=5.865 \\
& & Range=11 to 30
\end{tabular}

Note: Percentages may not total $100 \%$ because of rounding. 
more they will be prevented from living up to their potential. We therefore hypothesized that the more disadvantages the students have, the more they will benefit from participating in these programs and the more they will improve their DAT scores.

In summary, the first objective of our study was to explore whether DAT training programs increased the participants' PAT and AA scores. Our second objective was to explore whether the length of the program and personal factors (students' self-reported disadvantages, age, and standing in college) correlated with their DAT scores and the improvements in those scores over the course of the program.

\section{Methods}

This study was approved by the Institutional Review Board for the Behavioral and Health Sciences at the University of Michigan, Ann Arbor, MI. Data were collected from 361 participants in the PFS Program at the University of Michigan School of Dentistry between 1994 and 2011. However, no data were collected in 1996 and 2009. The participants were U.S. citizens or permanent residents of the United States and were recruited from various types of colleges and universities across the country.

The majority of the participants were female $(\mathrm{N}=221 ; 61$ percent) and African American $(\mathrm{N}=212$; 59 percent). Not all students provided all background information, so the percentages do not total 100 percent. In 2006, the State of Michigan passed a ballot initiative that banned preferential treatment on the basis of race, ethnicity, gender, or national origin in public education, public contracting, and public employment. Data on the applicants' ethnicity/ race have therefore not been collected since 2007 . Instead, these students indicated on their application forms whether they come from a disadvantaged background and whether they have a commitment to serve underserved patients in the future. Between 2001 and 2011, seventy-one program participants (27 percent) reported that they were from an economically disadvantaged background, eighty-two (31 percent) that they were from an educationally disadvantaged background, and 119 (45 percent) that they were socially disadvantaged. Between 2001 and 2006, 121 program participants ( 80 percent) reported that they were from an underrepresented minority background, and between 2007 and 2011, seventytwo (64 percent) indicated that they had a desire to serve underserved patients in the future. The students could report more than one disadvantage. When the sum of disadvantages was computed, 110 students (31 percent) reported that they had one disadvantage (31 percent), sixty students (17 percent) reported having two disadvantages, forty-three students (12 percent) reported having three disadvantages, and seven students ( 2 percent) reported that they had all three disadvantages plus wanted to serve underserved patients in the future.

The participants were selected for the program in an application process that consisted of a review of their qualifications. The program administrators selected participants based on their need for academic support and their potential to succeed in the dental school admission process if given opportunities to improve their test scores. This selection strategy implied that students with very strong natural science GPAs were less likely to be admitted into the program because of the assumption that they might qualify for dental school admission without any additional support services. In addition, students with very weak natural science GPAs were not considered because the program might not have addressed their needs adequately. Instead, students with natural science grades in the mid-range were invited to participate in the PFS Program.

The participants arrived in May and lived in campus housing during the program. A stipend covered the cost of room and board. The students took a diagnostic DAT before they participated in any test preparation classes to establish their baseline PAT and AA scores. The diagnostic testing and test preparation were provided by a nationally established test preparation program. In the middle of the program, the students took a second diagnostic DAT, and at the end of the program they participated in a final diagnostic DAT. Seventy former participants submitted their official DAT scores.

Other key features of this program were that the students worked on their materials for the dental school application process, including their personal statements. They also participated in mock interview sessions and received feedback concerning their learning styles. In addition, they attended lectures delivered by faculty members in various dental specialties and oral health care-related workshops that gave them opportunities to learn more about their future career. Exposing the students to preclinical activities and providing them with opportunities to shadow in the clinical setting rounded out their experiences. In order to investigate the objectives, the test preparation program shared the students' 
baseline, midpoint, and end point PAT and AA scores with the PFS Program administrators.

The data were analyzed with SPSS Version 18. Descriptive statistics such as frequencies, percentages, measures of central tendencies (means), and variability (standard deviations and ranges) were computed to provide an overview of the data. Repeated measures analyses of variance tests (ANOVAs) were conducted to compare the baseline with the midpoint and end of program scores as well as the baseline and the official scores. Spearman rho correlation coefficients were computed to analyze the relationship among the number of weeks in the program, the number of self-reported disadvantages, the students' age and standing in college, and their DAT scores.

\section{Results}

Before analyzing whether participation in the test preparation program affected the students' test performance, we provide an overview of the program and the student characteristics. From 1994 to 1999 , the program was offered as a four-week program for a relatively small number of students per year (eleven to fifteen per year). In 2000 and 2001, the number of weeks was increased to five and the number of participants to sixteen students. From 2002 to 2009 , the program was six weeks in length, and the number of students increased to up to thirty per year. Finally, in 2010 and 2011, the students participated in the program for seven weeks (see Table 1 for total number of students by length of program).

When considering the participant characteristics in Table 2, one must remember that not all students reported all of their background characteristics. This table therefore provides information about the frequencies with which specific characteristics were reported and the percentages of the total number of students who had certain characteristics. The sum of the percentages does not add up to 100 percent because the percentage of missing responses is not included.

A majority of the students were female (61 percent). Until 2006, the respondents reported their

\section{Table 2. Characteristics of program participants}

Number Percentage

Gender
Male
Female
Ethnicity/race
African American
Latino/a
Asian American
European American
Biracial
Middle Eastern
American Indian
Year of education
After sophomore year
After junior year
After senior year
One year or more after college graduation
Major
Natural science/engineering
Other
Disadvantaged
Economically
Educationally
Socially
Commitment to serve

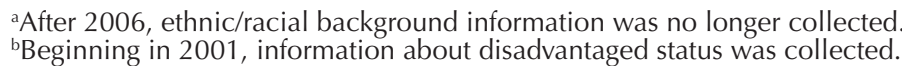

'Starting in 2007, information about commitment to serve was collected.

Note: Percentages do not total 100 percent because missing responses are not included. 
ethnicity/race on their application materials, and the data up to that point showed that 59 percent of the participants self-identified as African American and 10 percent as Latino/Hispanic. However, 23 percent did not report their ethnic/racial group. The participants ranged in age from twenty to thirty-seven years (Mean $=22.73$ years, $S D=2.666$ ). Most students attended the program after their junior year $(\mathrm{N}=107$; 30 percent) or senior year in college ( $\mathrm{N}=94 ; 26$ percent), with only 6 percent having graduated a year or more before attending the PFS Program. Most of the students who reported their course of study $(\mathrm{N}=164)$ majored in the natural sciences $(\mathrm{N}=132)$. Starting in 2001, applicants to the program indicated in their applications if they were economically, socially, and/ or educationally disadvantaged. In 2007, the program administrators added an additional background question concerning whether the students had a commitment to serve underserved patients. Table 2 provides an overview of the frequencies with which students reported these characteristics. Nearly half of the students (45 percent) reported since 2001 that they were socially disadvantaged, 31 percent that they were educationally disadvantaged, and 27 percent that they were economically disadvantaged. Nearly two-thirds of the participants (64 percent) since 2007 reported a commitment to serve underserved patients.
The participants' average PAT and AA scores at the beginning, midpoint, and end of the program for each of the sixteen years for which DAT data were collected are shown in Table 3. The results showed that the PAT and AA scores significantly increased over the course of the program in every single year. Overall, the PAT scores increased from a baseline average score of 14.40 to 17.09 at midpoint to 17.84 by the end of the program $(\mathrm{p}<0.001)$, and the AA scores increased from 13.53 to 14.09 to $15.12(\mathrm{p}<0.001)$.

For the early years of the program $(1994,1995$, 1997 to 1999 , and 2001 as well as for the last year 2011), the participants were encouraged to submit their official PAT and AA scores. The PAT scores did not substantially increase in the first two years of the program as well as in 1999 and 2000 (Table 3). However, overall the participants' official PAT scores were significantly higher than their baseline scores. By contrast, the official AA scores increased over the baseline scores for nearly all of the years.

The relationships between the participants' PAT and AA scores and the length of the program and their number of disadvantages, age, and standing in college were explored as well. We found that there was no relationship between these variables and the beginning AA scores (Table 4). This finding is likely to be due to the fact that all participants were selected

Table 3. Participants' average PAT and AA scores at the beginning, midpoint, and end of the PFS Program

\begin{tabular}{|c|c|c|c|c|c|c|c|c|c|c|c|c|c|c|}
\hline \multirow[b]{2}{*}{ Year } & \multicolumn{3}{|c|}{ PAT } & \multirow[b]{2}{*}{$\mathrm{p}$-value } & \multicolumn{2}{|c|}{ PAT } & \multicolumn{4}{|c|}{$\begin{array}{l}\text { Academic } \\
\text { Average }\end{array}$} & \multirow[b]{2}{*}{$\mathrm{p}$-value } & \multicolumn{3}{|c|}{$\begin{array}{l}\text { Academic } \\
\text { Average }\end{array}$} \\
\hline & $\begin{array}{l}\text { Base- } \\
\text { line }\end{array}$ & $\begin{array}{l}\text { Mid- } \\
\text { point }\end{array}$ & End & & $\begin{array}{l}\text { Base- } \\
\text { line }\end{array}$ & Official & $\mathrm{p}$-value & $\begin{array}{l}\text { Base- } \\
\text { line }\end{array}$ & $\begin{array}{l}\text { Mid- } \\
\text { point }\end{array}$ & End & & $\begin{array}{l}\text { Base- } \\
\text { line }\end{array}$ & Official & p-value \\
\hline 1994 & & & & & 14.70 & 14.80 & 0.927 & & & & & 13.50 & 14.90 & 0.007 \\
\hline 1995 & & & & & 14.33 & 14.33 & 1.00 & & & & & 13.44 & 15.78 & $<0.001$ \\
\hline 1996 & \multirow{3}{*}{\multicolumn{4}{|c|}{ No DAT data were collected. }} & \multicolumn{10}{|c|}{ No DAT data were collected. } \\
\hline 1997 & & & & & 13.31 & 15.00 & 0.043 & & & & & 13.00 & 15.39 & $<0.001$ \\
\hline 1998 & & & & & 13.09 & 16.00 & 0.051 & & & & & 13.09 & 15.64 & 0.006 \\
\hline 1999 & 13.50 & 16.19 & 17.81 & $<0.001$ & 16.25 & 17.25 & 0.092 & 13.31 & 13.56 & 14.69 & $<0.001$ & 15.25 & 18.25 & 0.069 \\
\hline 2000 & 14.08 & 15.92 & 16.54 & 0.018 & & & & 14.07 & 13.71 & 14.43 & 0.026 & & & \\
\hline 2001 & 15.06 & 17.75 & 18.88 & $<0.001$ & 16.25 & 17.25 & 0.092 & 14.18 & 14.25 & 15.69 & $<0.001$ & 15.25 & 18.25 & 0.069 \\
\hline 2002 & 14.79 & 15.36 & 16.64 & 0.009 & & & & 13.04 & - & 14.40 & $<0.001$ & & & \\
\hline 2003 & 13.92 & 16.38 & 18.04 & $<0.001$ & & & & 13.33 & 14.25 & 15.00 & 0.006 & & & \\
\hline 2004 & 13.38 & 17.46 & 17.63 & $<0.001$ & & & & 12.92 & 13.33 & 14.13 & $<0.001$ & & & \\
\hline 2005 & 13.96 & 17.50 & 17.75 & $<0.001$ & & & & 13.71 & 14.21 & 15.17 & $<0.001$ & & & \\
\hline 2006 & 14.62 & 17.17 & 17.89 & $<0.001$ & & & & 13.45 & 14.24 & 15.35 & $<0.001$ & & & \\
\hline 2007 & 15.40 & 17.40 & 18.30 & $<0.001$ & & & & 14.00 & 14.62 & 15.58 & $<0.001$ & & & \\
\hline 2008 & 14.65 & 16.88 & 16.65 & $<0.001$ & & & & 13.59 & 14.12 & 15.06 & $<0.001$ & & & \\
\hline 2009 & \multicolumn{4}{|c|}{ No DAT data were collected. } & \multicolumn{10}{|c|}{ No DAT data were collected. } \\
\hline 2010 & 14.13 & 18.50 & 18.88 & $<0.001$ & & & & 12.94 & 14.50 & 15.38 & $<0.001$ & & & \\
\hline 2011 & 15.33 & 17.52 & 18.37 & $<0.001$ & 15.32 & 18.05 & $<0.001$ & 13.59 & 14.11 & 15.63 & $<0.001$ & 14.05 & 17.46 & $<0.001$ \\
\hline Total & 14.40 & 17.09 & 17.84 & $<0.001$ & 14.42 & 16.15 & $<0.001$ & 13.53 & 14.09 & 15.12 & $<0.001$ & 13.61 & 16.23 & $<0.001$ \\
\hline
\end{tabular}


Table 4. Spearman's rho correlation coefficients between participants' PAT and AA scores and background characteristics

\begin{tabular}{lcccc} 
DAT Scores & Number of Program Weeks & Sum of Disadvantages & Age & Year in College \\
\hline Beginning AA & -0.02 & -0.02 & -0.13 & 0.01 \\
Beginning PAT & $0.16^{* *}$ & 0.08 & $0.22^{* *}$ & $0.14^{*}$ \\
Midpoint AA & 0.06 & 0.06 & $-0.17^{*}$ & -0.11 \\
Midpoint PAT & $0.19^{* *}$ & 0.01 & 0.00 & -0.01 \\
End of program AA & 0.06 & 0.01 & $-0.21^{*}$ & -0.10 \\
End of program PAT & 0.11 & 0.01 & -0.13 & -0.09 \\
Official AA score & $0.41^{* * *}$ & $0.43^{* * *}$ & -0.17 & -0.18 \\
Official PAT score & $0.53^{* * *}$ & $0.26^{*}$ & 0.06 & -0.10 \\
Official AA - beginning AA & $0.35^{* *}$ & 0.13 & -0.15 & -0.07 \\
Official PAT - beginning PAT & $0.24^{*}$ & & $-0.33^{* *}$ & -0.14 \\
${ }^{*} \mathrm{p}<0.05, * * p<0.01, * * * p<0.001$ & & & &
\end{tabular}

to have mid-range achievement scores in the natural sciences. However, the older the students were and the more advanced they were in their college education, the higher their baseline PAT scores were.

Considering the relationships between the length of the program (between four and seven weeks) and the participants' PAT and AA diagnostic scores, the data showed that the longer the program, the higher the students' midpoint PAT. Similarly, the longer the program, the higher the students' official PAT (rho $=0.53 ; \mathrm{p}<0.001)$ and AA $(r h o=0.41$; $\mathrm{p}<0.001$ ) scores were at the end of the program. The differences between the baseline and official scores both for the PAT $(r h o=0.24 ; p \leq 0.05)$ and the $\mathrm{AA}(\mathrm{rho}=0.35 ; \mathrm{p} \leq 0.01)$ increased with the length of the program.

Since 2001, the students reported how many disadvantages they had encountered. While there was no significant relationship between this personal characteristic and the diagnostic PAT and AA scores, there was a significant correlation between the sum of disadvantages and the participants' official AA $(\mathrm{rho}=0.43 ; \mathrm{p}<0.001)$ and official PAT $(\mathrm{rho}=0.40$; $\mathrm{p}<0.001$ ) scores (Table 3 ). The higher the number of disadvantages, the more the students had improved their AA scores from the baseline to the official scores $(\mathrm{rho}=0.26 ; \mathrm{p}<0.05)$.

The participants' age correlated with their baseline PAT scores positively: the older the students were, the higher their PAT baseline scores $(\mathrm{rho}=0.22$; $\mathrm{p}<0.01)$. However, the older the students were, the lower their midpoint AA scores $(r h o=-0.17 ; p<0.05)$ and their AA scores at the end of the program $(\mathrm{rho}=$ $-0.21 ; p<0.05$ ). The only relationship between the students' standing in college and their DAT scores was that the older the students, the higher their beginning PAT scores $(\mathrm{rho}=0.14 ; \mathrm{p}<0.05)$.

In addition to computing these correlation coefficients between the participants' DAT scores and the program and student characteristics, stepwise multivariate regression analyses with the dependent variable "Difference between the End and the Beginning AA scores" and the dependent variable "Difference between the End and the Beginning PAT scores" and the four independent variables "age," "year in college," "number of disadvantages," and "number of weeks in program" were computed as well. The results showed that the number of program weeks was a significant predictor of the degree of improvement in the participants' AA scores from the beginning to the end of the program, while neither their age, number of disadvantages, nor year in college was a significant predictor of this type of improvement (number of program weeks: standardized Beta coefficient $=0.177$; $p=0.036$ ). The longer the program lasted, the more the participants' AA scores improved. However, their age was the only significant predictor of the difference between the end and the beginning PAT scores (standardized Beta coefficient $=-0.330 ; \mathrm{p}<0.001$ ). The older the students, the less their PAT scores improved.

\section{Discussion}

In 2004, Veal et al. reported that students from URM groups faced major challenges when preparing for the dental school admission process because they had critical gaps in their knowledge concerning how to prepare themselves academically for dental school and the dental school admission process. ${ }^{18}$ Including 
predental students therefore in summer enrichment programs for students interested in medical careers was a logical next step because research had shown that these programs were quite successful in increasing the students' success in the medical school admissions process. ${ }^{8,9,12,19}$ In 2010, Alexander and Mitchell reported that participation in summer enrichment programs indeed had a positive effect on increasing the number of predental students from URM backgrounds who were enrolled in dental schools. ${ }^{20}$

One of the factors considered in all admissions processes for dental school (whether holistic ${ }^{21}$ or quantitatively oriented) is the applicants' DAT scores. Some summer enrichment programs such as the PFS Program at the University of Michigan include preparation programs for the DAT. While two studies have explored the effectiveness of test preparation courses for the Medical College Admission Test (MCAT), ${ }^{14,22}$ no research prior to our study has analyzed whether these programs actually increased the students' PAT and AA scores on the DAT nor sought to identify which characteristics of the test preparation program or the participants might be related to a potential increase in scores.

Our study showed that these test preparation programs actually did increase the participants' PAT and AA scores from the beginning to the end of the program. However, these findings should not be generalized to students who take DAT preparation programs in general. Instead, these findings have to be interpreted in the context of our participants' characteristics and the fact that this DAT training was part of a summer enrichment program for students from disadvantaged backgrounds. It is important to realize that only students with intermediate academic achievement scores in the natural sciences had been admitted to the program. Students with higher basic science GPAs or with extremely low GPAs were not invited to participate. The findings of this study are therefore clearly limited to a subset of students and do not necessarily apply to predental students in general. In addition, the admitted students did not merely participate in a test preparation program. Instead, the DAT preparation course was embedded in a larger set of classes that aimed to increase the participants' motivation, interest, and knowledge about dentistry and to prepare them more fully for the admissions process. It is possible that these additional enrichment program offerings had a strong motivating effect on the students and thus supported the test preparation efforts. Our findings should therefore be interpreted as indicating that DAT preparation courses can in- crease the PAT and AA scores of students who had previously not succeeded in obtaining the highest academic achievement in basic science courses and who participate in a program that prepares them not just for the DAT but also for other facets of the admissions process.

Given that the participants' DAT scores did improve over the course of the program, the next question is how these programs should be designed and which student characteristics should be considered to optimize chances of selecting the participants most likely to benefit from the experience. The results of the correlational analyses showed that the program length was not significantly correlated with the end of program diagnostic PAT and AA scores. However, the results of a multivariate regression analysis demonstrated that the number of program weeks was a significant predictor of improvement from beginning to end. This finding points to the importance of considering the differences in the participants' beginning AA scores when discussing their end scores. In addition, it is also interesting to note that the program length was strongly correlated with the official PAT and AA scores. One could interpret this finding as indicating that the more weeks of support the students received during the test preparation program, the more likely they were to continue successfully in their preparation after it ended.

In pursuing a better understanding of who should be selected for summer enrichment programs, the data showed that year in college was not related to program success. However, the older the participants were, the less their AA scores had improved by the end of the program and the less their official PAT scores had increased from the beginning of the program. This PAT-related finding should be interpreted in connection with the fact that the older the participants, the higher their beginning PAT scores already were. The results of the multivariate regression analysis with the dependent variable "Difference between the End and Beginning PAT scores" showed that the participants' age was the only significant predictor of their improvement. This finding provides further evidence for the hypothesis that considering the students' age is important. Program administrators might consider this finding as support for a strategy to recruit students into these programs as early as their academic preparation allows them to follow the materials presented in test preparation courses.

Finally, it might also be worthwhile for program administrators to consider that the more disadvantages the participants self-reported, the more 
their official scores increased from their baseline scores. This finding points to the importance of offering support services to students from disadvantaged backgrounds as suggested in the Sullivan report. ${ }^{1}$

This study had several limitations. First of all, the students were not randomly selected into the training program. They had self-selected to apply, and the program administrators had selected them based on their previous achievement in the basic sciences in the middle range. Second, summer enrichment programs offer much more than merely test preparation courses. They engage the students in other preparation for their application to dental schools, such as mock interviews and preparing written application materials. These programs also offer a variety of experiences related to having a career in dentistry. All of these additional activities might increase the students' interest in dentistry as a career and thus motivate them to work hard in the test preparation program. In addition, being part of a small group of students with similar backgrounds and interests can provide emotional and social support that students who take test preparation courses individually might not have. Finally, having students self-report their disadvantages might be subjective. It is therefore recommended to use objective indicators in future research.

\section{Conclusions}

DAT preparation courses presented as part of a summer enrichment program for students from disadvantaged backgrounds with mid-level performances in basic science college classes allowed these students to increase their PAT and AA scores significantly over the course of the program. The longer the courses were, the higher the students' official PAT and AA scores were and the more the students improved from the baseline testing to the official testing. The more self-reported disadvantages the students had, the more their official PAT and AA scores increased. The older the students were, the less their end of program diagnostic AA scores increased, and the less their official PAT scores increased over their baseline scores.

This study demonstrates that programs like the PFS Program can be effective tools to increase the competitiveness of students from URM and disadvantaged backgrounds for the admissions process to dental and perhaps other health professions schools. They thus contribute to increasing access to satisfying careers in the health professions for persons who might otherwise be missing among health professionals.

\section{Acknowledgment}

This study was supported by HCOP Grant \# D18HP13634 (PI: Dr. Marilyn Woolfolk).

\section{REFERENCES}

1. Missing persons: minorities in the health professions. A report of the Sullivan Commission on Diversity in the Healthcare Workforce. Atlanta: Sullivan Commission, 2004.

2. Woolfolk MW, Price SS. Efforts to increase student diversity in allied, predoctoral, and advanced dental programs in the United States: a historical perspective. J Dent Educ 2012;76(1):51-64.

3. Smedley BD, Stith AY, Nelson AR, eds. Unequal treatment: confronting racial and ethnic disparities in health care. A report by the Committee on Understanding and Eliminating Racial and Ethnic Disparities in Health Care, Institute of Medicine. Washington, DC: National Academies Press, 2003.

4. Moy E, Bartman BA. Physician race and care of minority and medically indigent patients. JAMA 1995;273(19): 1515-20.

5. Komaromy M, Grumback K, Drake M, Vranizan K, Lurie $\mathrm{N}$, Keane D, Bindman AB. The role of black and Hispanic physicians in providing health care for underserved populations. New Engl J Med 1996;334(20):1305-10.

6. Cantor JC, Miles EL, Barker DC, Baker LC. Physician service to the underserved: implications for affirmative action in medical education. Inquiry 1996;33(2):167-80.

7. Davidson RC, Lewis EL. Affirmative action and other special consideration admissions at the University of California, Davis, School of Medicine. JAMA 1997;278(14):1153-8.

8. Strayhorn G. A pre-admission program for underrepresented minority and disadvantaged students: application, acceptance, graduation rates, and timeliness of graduating from medical school. Acad Med 2000;75(4):355-61.

9. Strayhorn G. Participation in a premedical summer program for underrepresented minority students as a predictor of academic performance in the first three years of medical school. Acad Med 1999;74(4):131-43.

10. Strayhorn MD, Demby K. Do pre-admission programs make a difference in the enrollment of underrepresented minority students at U.S. medical schools? Acad Med 1999;74(4):431-4.

11. Blakely AW, Broussard LG. Blueprint for establishing an effective postbaccalaureate medical school pre-entry program for educationally disadvantaged students. Acad Med 2003;78(5):437-47.

12. Gravely T, McCann A, Brooks E, Harman W, Schneiderman E. Enrichment and recruitment programs at dental schools: impact on enrollment of underrepresented minority students. J Dent Educ 2004;68(5):542-52.

13. Markel G, Woolfolk MW, Inglehart MR. Feeding the pipeline: academic skills training for predental students. J Dent Educ 2008;72(6):653-61. 
14. McGaghie WC, Downing SM, Kubilius R. What is the impact of commercial test preparation courses on medical examination performance? Teach Learn Med 2004;16(2):202-11

15. U.S. Department of Health and Human Services. The 2011 HHS poverty guidelines. At: http://aspe.hhs.gov/ poverty/11poverty.shtml. Accessed: October 16, 2011.

16. Barron's profiles of American colleges. $29^{\text {th }} \mathrm{ed}$. Hauppauge, NY: College Division of Barron's Educational Series, 2008.

17. U.S. Department of Health and Human Services, Health Resources and Services Administration. Health Careers Opportunity Program. At: http://bhpr.hrsa.gov/grants/ diversity/hcop.html. Accessed: July 11, 2013.

18. Veal K, Perry M, Stavisky J, D'Abreu K. The pathway to dentistry for minority students: from their perspective. J Dent Educ 2004;68(9):938-46.
19. Price SS, Brunson WD, Mitchell DA, Alexander CJ, Jackson DL. Increasing the enrollment of underrepresented minority dental students: experiences from the dental pipeline program. J Dent Educ 2007;71(3):339-47.

20. Alexander CJ, Mitchell DA. The role of enrichment programs in strengthening the academic pipeline to dental education. J Dent Educ 2010;74(10 Suppl):S110-20.

21. Lacy ES, McCann AL, Miller BH, Solomon E, Reuben JS. Achieving student diversity in dental schools: a model that works. J Dent Educ 2012;76(5):523-33.

22. Grumbach K, Chen E. Effectiveness of University of California postbaccalaureate premedical programs in increasing medical school matriculation for minority and disadvantaged students. JAMA 2006;296(9):1079-85. 